\title{
Effects of mechanical intervention on cutaneous sensory change and pressure pain threshold in the same spinal segment of myofascial pain
}

\author{
Do Hyung Kim ${ }^{a}$, Su-Hyun Lee ${ }^{b}$, Byoung Hee Lee ${ }^{b}$ \\ ${ }^{a}$ Department of Medical Rehabilitation Science, Yeoju Institute of Technology, Yeoju, Republic of Korea \\ ${ }^{b}$ Department of Physical Therapy, College of Health Science and Social Welfare, Sahmyook University, Seoul, Republic of Korea
}

\begin{abstract}
Objective: The purpose of this study was to identify whether cutaneous sensory (CS) changes induced by mechanical intervention (MI) increases the trigger point threshold of the same spinal segment as well as to investigate the relationship between the amounts of change in CS pressure pain thresholds (PPT).
\end{abstract}

Design: Randomized controlled trial.

Methods: Thirty-nine persons with myofacial pain (MFP) were recruited in this experiment. The subjects consisted of 20 men and 19 women (age 20-39). MI was applied on the subjects using the Graston technique for 5 minutes to induce CS changes. The CS changes were measured with sensory tests by using the Von Frey Filament, and PPT changes were estimated by using the pressure threshold meter. For the observation of sensory and PPT changes with time, the test was conducted for 15 minutes including a pre, post, and after intervention session.

Results: CS threshold increased significantly when MI was applied $(p<0.001)$. On the same spinal segment, changes in the right infraspinatus PPT was observed $(p<0.001)$ but the PPT changes in other muscles were not significantly different. Furthermore, the control group CS and PPT were not significantly different. In addition, regression analysis showed that the CS changes have a larger impact on PPT in the same spinal segment $(p<0.001)$.

Conclusions: CS changes induced by MI make to change PPT on the same spinal segment. In other words, it is possible to identify PPT changes following CS changes except for the muscle which belongs to a different spinal segment. Therefore, application of MI is necessary for the CS changes in the same spinal segment. Furthermore, it can be useful in the clinical fields as a method of providing pain control and increasing the PPT.

Key Words: Central nervous system sensitization, Mechanical phenomena, Sensitivity, Trigger points

\section{Introduction}

Myofascial pain (MFP) is defined as muscles that are in a contracted or shortened state with increased stiffness and tone, and contain trigger points [1]. Due to MFP, continued muscle spasm and contractile unit shortening can cause damage of the soft tissues, which may precipitate the synthesis of inflammatory substances and the release of endogenous algogenic biochemicals that enhances nociception $[2,3]$.
The main cause of MFP is mostly affected by the activity of the myofascial trigger points $[4,5]$. Therefore, in order to reduce MFP, it is important to reduce the activity of the trigger points and to find out the mechanism of the occurrence of trigger points.

Intramuscular pain receptors respond sensitively to mechanical stimulation, such as pressure, rubbing, twisting, and stretching [6]. The application of mechanical stimulation is used to stimulate the extracellular matrix to re-

Received: 26 February, 2019 Revised: 15 March, 2019 Accepted: 18 March, 2019

Corresponding author: Byoung Hee Lee (ORCID https://orcid.org/0000-0001-9766-6068)

Department of Physical Therapy, College of Health Science and Social Welfare, Sahmyook University, 815 Hwarang-ro, Nowon-gu, Seoul 01795 , Republic of Korea Tel: 82-2-3399-1634 Fax: 82-2-3399-1639 E-mail: 3679@syu.ac.kr

(c) This is an Open-Access article distributed under the terms of the Creative Commons Attribution Non-Commercial License (http://creativecommons.org/licenses/ by-nc/4.0) which permits unrestricted non-commercial use, distribution, and reproduction in any medium, provided the original work is properly cited.

Copyright (๑ 2019 Korean Academy of Physical Therapy Rehabilitation Science 
generate fibroblasts, including collagen, elastin, cytokines, and growth factors [7]. The Graston technique is a mechanical stimulation method to assist the recovery of intertwined and adherent fibers in the muscles, to control the pain caused by MFP symptoms, to increase the range of motion, and to prevent chronicity of the disease [8,9].

When the sensitizing input in the myofacial trigger point is sent to the spinal cord, it causes spinal segmental sensitization associated with referred pain, resulting in pain within the same spinal segment [10]. Furthermore, a strong physical connection between the clinical signs of trigger points and spinal segment sensitization has been found [11]. In previous studies, capsaicin was injected into the skin segment C5 to sensitize the spinal segment and it was reported that the pressure pain threshold (PPT) decreased in the same spinal segmental nerve as the ingraspinatus [12]. Animal studies have shown that trigger points can be removed by an incision in the motor nerve or injection of lidocaine; however, the trigger points other than the segment level of the muscle contacting the trigger point were not changed [13]. To date, research suggests that MFP with characteristic trigger points can be explained by a partial spinal reflex disorder [13].

Based on the previous research results, the focus of this study was to investigate whether the reactivity of the painful trigger point was related to the spinal segment. Contrary to the previous view that the point of origin of MFP is caused by pathologic induction, this study hypothesized that MFP is caused by neurological mechanism and central sensitization. Therefore, the purpose of this study was to determine the relationship between the PPT at the site of pain in the same myotome area and the sensory changes of the area through mechanical stimulation.

\section{Methods}

\section{Participants}

In this study, 39 subjects were randomly assigned into the mechanical intervention (MI) group $(n=19)$ or the control group $(n=20)$. The subjects consisted of 20 men and 19 women (age 20-39). The subjects were recruited from a hospital located in Suwon, and were randomly allocated to the MI or control group by using an online randomization tool (https://www.random.org/). The criteria for recruiting the subjects were those who had MFP but did not have a history of musculoskeletal surgery, and had no upper limb blood circulation disorders or sensory disturbances. Subjects with upper limb blood circulation disorders, upper limb sensory loss, or sensory hypersensitivity were excluded from the study. This study was approved by the Institutional Review Board of Sahmyook University (IRB No. 2-1040781-ABN-01-2017005HR), and all participants provided written informed consent to participate.

\section{Procedures}

This study was a double-blinded, randomized comparative trial. One of the experimenters performed the sensory and PPT test before and after intervention, and the other experimenter conducted MI for the assessment of cutaneous sensory (CS) changes. MI was performed using the Graston technique (GT-2; Graston Technique instrument, Indianapolis, IN, USA) without any slush. In order to equalize the amount of stimulation through the Graston technique, a metronome was used and mechanical friction was applied for 5 minutes at a frequency of 2 times/sec. MI was performed after the primary sensory test was completed using a randomized method and stimulation was performed on the skin outside of the right upper arm of the subject.

\section{Measurement tools}

\section{Sensory test (Von Frey filament test)}

Sensory tests were performed using the Von Frey filament (North Coast) consisting of a total of 20 monofilaments that were used primarily for the measurement of sensory function (Figure 1). The Von Frey filament test has a high reliability with a high test-retest reliability ( $\mathrm{ICC}=0.760-0.983$ ) [14]. From the evidence of a previous study, seven filaments (2.44 g, $2.83 \mathrm{~g}, 3.22 \mathrm{~g}, 3.61 \mathrm{~g}, 3.84 \mathrm{~g}, 4.08 \mathrm{~g}$, and $4.31 \mathrm{~g}$ ) among the 20 filaments were selected and were subjected to a sensory test [15]. The progression of the examination was made by selecting the point of choice with a radius of $3 \mathrm{~cm}$ just outside the upper limb of the subject. Pressure was applied to the recorded point with a constant force until the filament length was bent $1 / 2$ of its length for 2 seconds using a filament (Figure 2). When the pressure was applied by the experimenter, the subject was instructed to give a signal to the experimenter if they experienced the force to a level of pain. The test was carried out in succession starting from a small value filament and each filament was measured three times with the lowest value among the three filament senses recorded [15]. After the intervention, the experimenter performed the sensory test in the same way as before the experiment, at the site where the subjects were not aware of whether the intervention was applied or not. In order to confirm the recovery time of the sensory points after the experiment, the 


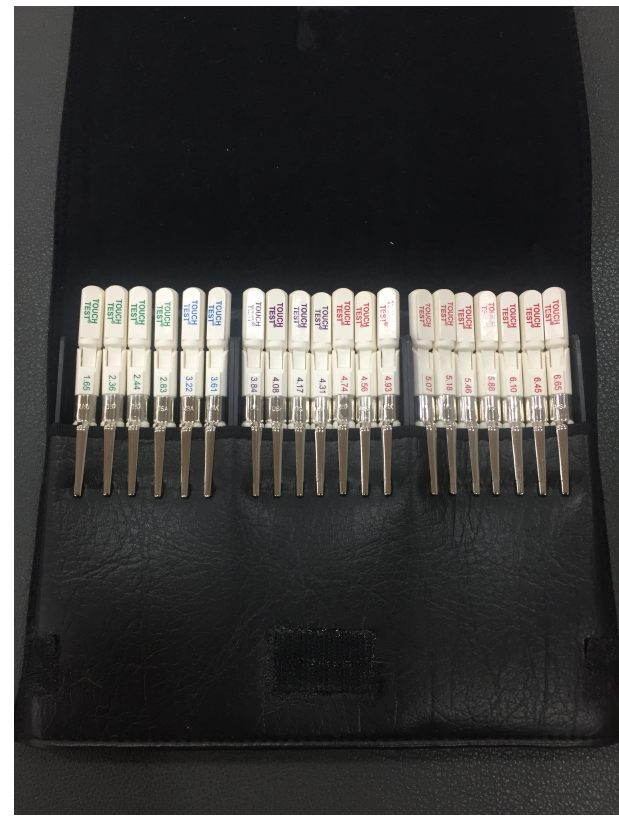

Figure 1. Von Frey filaments.

same method was used for 15 minutes after the experiment and a total of 3 sensory tests were performed. To ensure the reliability and consistency of the test, the progress of the test was checked by a skilled person with more than 8 years of clinical experience.

\section{Pressure pain threshold test}

The PPT test was measured using a pressure threshold meter (Pain diagnostics and Thermography, USA). The PPT test has a high reliability with a high test-retest reliability (ICC=0.955-0.996) [14]. After the sensory test was completed, the subject was placed on the bed and was subjected to PPT measurement. The measurement site was the pain inducing part of both infraspinatus muscles which are under the control of the neurological level C5, and bilateral trapezius with different neurological control. PPT measurements were performed by marking the area of the skin that was the point of pain, and the experimenter measured the pain by applying gradual pressure using a pressure threshold meter (Figure 3). When gradual pressure was applied, the subject signaled to the experimenter at the time of when pain was experienced at the pressure site, and the pressure threshold meter value was recorded at that time as the PPT value [16]. In this way, the measurement was performed three times for each painful trigger point and the average of the two closest values were recorded as data. After the intervention, the subject performed the PPT test in the same

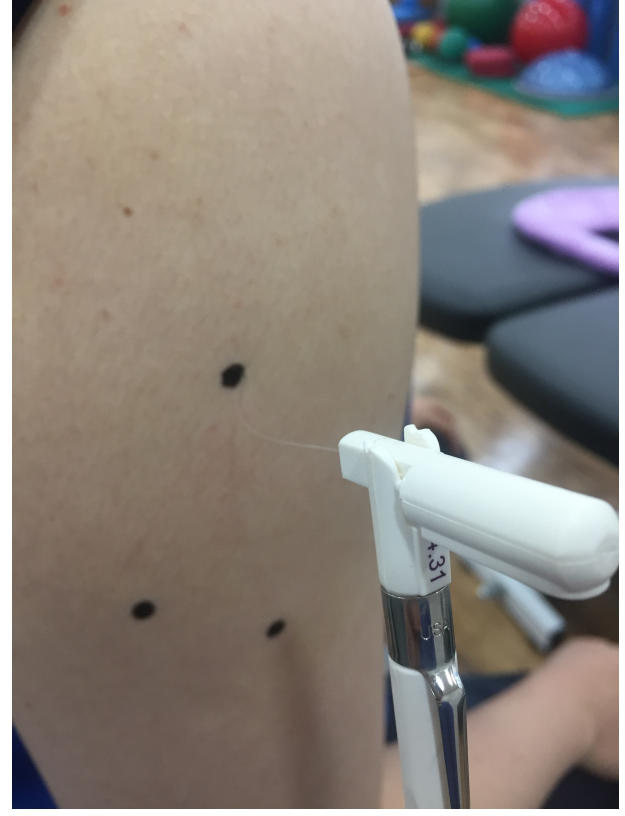

Figure 2. Sensory test by using Von Frey filament.

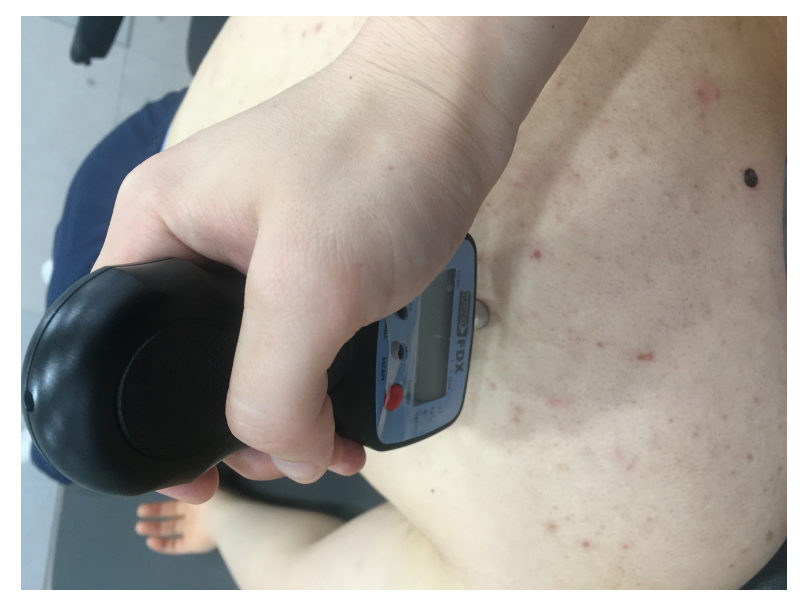

Figure 3. Infraspinatus's pressure pain thresholds test using by pressure threshold meter.

method as before the experiment in the area where the subject was not aware of whether the intervention was applied or not. In order to confirm the changes in PPT after the experiment, the same method was applied 15 minutes after the experiment and total of 3 PPT tests were performed. To ensure the reliability and consistency of the test the progress of the test was assessed by one experimenter.

\section{Statistical analysis}

The IBM SPSS Statistics ver. 21.0 software (IBM Co., Armonk, NY, USA) was used to analyze the descriptive sta- 
tistics and general characteristics. Friedman test and Wilcoxon sign rank test were performed to observe changes in CS during MI. The two-way repeated measures ANOVA was performed for both the trapezius and infraspinatus muscle to observe changes in the PPT according to MI. Tukey HSD was used for the post-hoc test for changes in the PPT. In addition, regression analysis was performed to examine the effect of changes in CS on the change in PPT. Statistical significance was set at $p<0.05$ in this study.

\section{Results}

\section{General characteristics of subjects}

Thirty-nine subjects participated in this study. Demographic characteristics are shown in Table 1.

\section{Sensory test}

The changes in sensory test results are as follows in Table 2. Statistical analysis using the Friedman test showed statically significant increases in sensory changes after MI with the Graston technique $\left(\mathrm{x}^{2}=20.037, p<0.001\right)$. According to the post-hoc results, there was a statistically significant difference on the sensory changes in the control group compared with the MI group after intervention ( $\mathrm{z}=-4.064, p=0.000)$. In the control group, the sensory changes immediately after the intervention were not statistically significant $(\mathrm{z}=-1.531$, $p=0.101$ ). After 15 minutes of stimulation, the sensory changes were statistically significant difference compared to control group, as similar result after the stimulation $(\mathrm{z}=-5.412$, $p=0.000$ ). However, there were no statistical significance for changes in CS after 15 minutes of intervention in the control group $(\mathrm{z}=-1.824, p=0.068)$.

\section{PPT}

\section{PPT changes in the right infraspinatus}

The changes in the right infraspinatus PPT results are as follows in Table 3. Statistical analysis using the two-way re- peated measures showed statically significant increases in changes of PPT after MI with the Graston technique $(\mathrm{F}=13.037, p<0.05)$. Furthermore, statistically significant differences were found in the PPT data for the time $\mathrm{x}$ treatment interactions $(\mathrm{F}=8.529, p<0.05)$. According to post-hoc results, there was a statistically significant difference in the PPT of the control group compared with the MI group after intervention $(p<0.001)$. In the control group, the changes in PPT immediately after the intervention were not statistically significant ( $p=0.983$ ). After 15 minutes of stimulation, the changes in PPT were significantly different compared to the control group which was similar to the results after the stimulation $(p<0.05)$. However, there was no statistical significance for changes of PPT after 15 minutes of intervention in the control group ( $p=0.379)$.

\section{PPT changes in the left infraspinatus}

Changes in the left infraspinatus PPT results are as follows in Table 3. Statistical analysis using the two-way repeated measures showed no significant differences in changes of PPT after MI with the Graston technique $(\mathrm{F}=0.110, p=0.742)$, and changes in the PPT for differences between groups also did not reveal a significant difference $(\mathrm{F}=3.558, p=0.067)$. In addition, statistically significant differences were not found in the PPT data for the time $\mathrm{x}$ treatment interactions $(\mathrm{F}=3.026, p=0.090)$.

Table 1. General characteristics of subjects

$(\mathrm{N}=39)$

\begin{tabular}{lcc}
\hline \multicolumn{1}{c}{ Characteristic } & MI group $(\mathrm{n}=19)$ & Control group $(\mathrm{n}=20)$ \\
\hline Sex (male/female) & $11 / 8$ & $9 / 11$ \\
Age $(\mathrm{y})$ & $32.19(5.18)$ & $30.47(4.16)$ \\
Height $(\mathrm{cm})$ & $169.11(9.54)$ & $167.70(8.69)$ \\
Weight $(\mathrm{kg})$ & $66.65(12.97)$ & $62.18(14.69)$ \\
\hline
\end{tabular}

Values are presented as number only or mean (SD). MI: mechanical intervention.

Table 2. Comparisons of sensory changes

$(\mathrm{N}=39)$

\begin{tabular}{lcccccc}
\hline \multicolumn{1}{c}{ Group } & Pre $\left(\mathrm{kg} / \mathrm{cm}^{2}\right)$ & $\begin{array}{c}\text { After 1 min } \\
\left(\mathrm{kg} / \mathrm{cm}^{2}\right)\end{array}$ & $\begin{array}{c}\text { After 15 min } \\
\left(\mathrm{kg} / \mathrm{cm}^{2}\right)\end{array}$ & $\begin{array}{c}\text { Pre-After 1 min } \\
p \text {-value }\end{array}$ & $\begin{array}{c}\text { After 1 min-After } \\
15 \text { min } p \text {-value }\end{array}$ & $\begin{array}{c}\text { Pre-After } \\
15 \text { min } p \text {-value }\end{array}$ \\
\hline MI group $(\mathrm{n}=19)$ & $3.55(0.32)$ & $3.97(0.24)$ & $3.89(0.20)$ & $<0.001$ & 0.045 & $<0.001$ \\
Control group $(\mathrm{n}=20)$ & $3.61(0.32)$ & $3.68(0.36)$ & $3.66(0.34)$ & 0.101 & 0.296 & 0.068 \\
$p$-value & 0.544 & 0.010 & 0.023 & & & \\
\hline
\end{tabular}

Values are presented as mean (SD).

MI: mechanical intervention, After 1 min: after 1 minutes evaluation, After 15 min: after 15 minutes evaluation. 
Table 3. Comparisons of pressure pain threshold changes in infraspinatus

$(\mathrm{N}=39)$

\begin{tabular}{|c|c|c|c|c|c|c|}
\hline Group & $\operatorname{Pre}\left(\mathrm{kg} / \mathrm{cm}^{2}\right)$ & $\begin{array}{l}\text { After } 1 \text { min } \\
\left(\mathrm{kg} / \mathrm{cm}^{2}\right)\end{array}$ & $\begin{array}{l}\text { After } 15 \text { min } \\
\left(\mathrm{kg} / \mathrm{cm}^{2}\right)\end{array}$ & $\begin{array}{c}\text { Pre-After } 1 \text { min } \\
p \text {-value }\end{array}$ & $\begin{array}{l}\text { After } 1 \text { min-After } \\
15 \min p \text {-value }\end{array}$ & $\begin{array}{c}\text { Pre-After } \\
15 \text { min } p \text {-value }\end{array}$ \\
\hline \multicolumn{7}{|l|}{ Right } \\
\hline MI group $(n=19)$ & $3.33(0.98)$ & $3.88(0.97)$ & $3.94(0.88)$ & $<0.001$ & 0.109 & 0.001 \\
\hline Control group $(n=20)$ & $3.45(0.94)$ & $3.44(0.95)$ & $3.38(1.01)$ & 0.983 & 0.309 & 0.379 \\
\hline$p$-value & 0.198 & 0.039 & 0.018 & & & \\
\hline \multicolumn{7}{|l|}{ Left } \\
\hline MI group (n=19) & $3.27(0.77)$ & $3.46(0.73)$ & $3.50(0.70)$ & 0.052 & 0.594 & 0.057 \\
\hline Control group $(n=20)$ & $3.54(0.98)$ & $3.49(1.01)$ & $3.53(1.04)$ & 0.270 & 0.428 & 0.854 \\
\hline$p$-value & 0.069 & 0.057 & 0.054 & & & \\
\hline
\end{tabular}

Values are presented as mean (SD).

MI: mechanical intervention, After $1 \mathrm{~min}$ : after 1 minutes evaluation, After 15 min: after 15 minutes evaluation.

Table 4. Comparisons of pressure pain threshold changes in trapezius

$(\mathrm{N}=39)$

\begin{tabular}{|c|c|c|c|c|c|c|}
\hline Group & Pre $\left(\mathrm{kg} / \mathrm{cm}^{2}\right)$ & $\begin{array}{l}\text { After } 1 \text { min } \\
\left(\mathrm{kg} / \mathrm{cm}^{2}\right)\end{array}$ & $\begin{array}{l}\text { After } 15 \min \\
\left(\mathrm{kg} / \mathrm{cm}^{2}\right)\end{array}$ & $\begin{array}{c}\text { Pre-After } 1 \text { min } \\
p \text {-value }\end{array}$ & $\begin{array}{l}\text { After } 1 \text { min-After } \\
15 \min p \text {-value }\end{array}$ & $\begin{array}{c}\text { Pre-After } \\
15 \text { min } p \text {-value }\end{array}$ \\
\hline \multicolumn{7}{|l|}{ Right } \\
\hline MI group $(n=19)$ & $2.72(0.57)$ & $2.53(0.43)$ & $2.48(0.43)$ & 0.061 & 0.456 & 0.071 \\
\hline Control group $(n=20)$ & $2.78(0.66)$ & $2.59(0.61)$ & $2.53(0.57)$ & 0.060 & 0.161 & 0.070 \\
\hline$p$-value & 0.770 & 0.386 & 0.649 & & & \\
\hline \multicolumn{7}{|l|}{ Left } \\
\hline MI group $(\mathrm{n}=19)$ & $2.62(0.72)$ & $2.51(0.78)$ & $2.48(0.71)$ & 0.126 & 0.713 & 0.120 \\
\hline Control group $(n=20)$ & $2.69(0.76)$ & $2.48(0.51)$ & $2.42(0.52)$ & 0.073 & 0.266 & 0.070 \\
\hline$p$-value & 0.880 & 0.767 & 0.714 & & & \\
\hline
\end{tabular}

Values are presented as mean $(\mathrm{SD})$.

MI: mechanical intervention, After 1 min: after 1 minutes evaluation, After 15 min: after 15 minutes evaluation.

\section{PPT changes in the right trapezius}

Changes in the right trapezius PPT results are as follows in Table 4. Statistical analysis using the two-way repeated measures showed no significant difference in changes of PPT after MI with the Graston technique ( $\mathrm{F}=3.331, p=0.076)$, and changes in the PPT for differences between groups also did not reveal a statistically significant difference $(\mathrm{F}=0.018$, $p=0.894)$. In addition, statistically significant differences were not found in the PPT data for the time $\mathrm{x}$ treatment interactions $(\mathrm{F}=0.024, p=0.879)$.

\section{PPT changes in the left trapezius}

Changes in the left trapezius PPT results are as follows in Table 4. Statistical analysis using the two-way repeated measures showed no significant differences in changes of PPT after MI with the Graston technique ( $\mathrm{F}=1.989, p=0.167)$, and changes in the PPT for differences between groups also did not reveal a statistically significant difference $(\mathrm{F}=0.943$, $p=0.338$ ). In addition, statistically significant differences were not found in the PPT data for the time $\mathrm{x}$ treatment in- teractions $(\mathrm{F}=0.186, p=0.668)$.

\section{Regression results between sensory and PPT changes}

In the results of the two-way repeated measures analysis of variance, the regression analysis was conducted to investigate the relationship between changes of sensory and PPT values for the right infraspinatus muscle only, which showed a significant relationship between the independent and dependent variables $(\mathrm{F}=15.276, p<0.001)$. A multiple linear regression using dummy variables represented that $30 \%$ of the variance in changed PPT is considered for by knowing the change in sensory changes $\left(\mathrm{r}^{2}=0.298\right)$.

\section{Discussion}

This study was designed to investigate the relationship between changes in CS in the spinal segment C5 and changes in the PPT of the muscle in the same spinal segment when MI was applied using the Graston technique. In addition, regression analysis was performed to confirmed the re- 
lationship between CS and PPT changes.

The changes in CS and PPT during MI using the Graston technique showed that $\mathrm{CS}$ changes tend to decrease after stimulation and recover $50 \%$ of the CS after 15 minutes. Changes in PPT appeared in the right infraspinatus but there were no changes in the PPT in the other muscles undergoing other spinal segment control. This result is interpreted as the lateral part of the right upper extremity and the right infraspinatus under the CS changes are dominated by the same spinal segment. Within the same spinal segment, it was revealed that all of the functional elements of the spinal segment, such as skin segment, muscle segment and joint have the same effect on hyperexcitable and hyperactivity [17]. Previous studies reported that when mechanical stimulus was applied to the spinal joints, the PPT of the upper trapezius changed the same spinal segment as the treated joint increased [18]. This suggests that mechanical stimulation applied to the vertebrae may increase the activity of the periaqueductal gray matter around the midbrain and produce a central hypoalgesic effect. Therefore, the effect of MI applied in this study is presumed to be the effect of pain reduction due to the production of endogenous opioids [19].

Despite the changes in CS after MI, PPT changes were not observed in other muscles except for the right infraspinatus. It is considered that the absence of PPT changes in the right trapezius muscle was not affected by intervention because it was under the control of the other spinal segment on the area where the CS was reduced [20]. In addition, the absence of changes in the PPT in the left trapezius and infraspinatus seems to be due to the fact that the neurotransmitter did not affect the other side of the stimulus applied on the basis of the mid-sagittal plane [21]. Generally, the pain stimulation due to the repeated pressure threshold measurement at the same site is transmitted, resulting in peripheral sensitization and a decrease in the PPT [22,23]. However, this study did not show a tendency for the PPT to decrease significantly in all muscles, so it seems as though the peripheral sensitization did not appear.

Regression analysis of the right infraspinatus, which showed a statistically significant difference between changes in CS and PPT, showed that the change in CS had an effect on the change of PPT in the same spinal segment. In previous studies, it was reported that PPT changes in the same spinal segment at the time of CS changed by capsaicin injection [12], and the same relationship was also observed in electrical stimulation [14]. Therefore, the amount of change in PPT altered according to the degree of change in the CS, so that if the amount of change in the CS was increased through more stimulation, the amount of change in the PPT value may have increased.

However, the limitation of this study was the lack of time to confirm the changes in CS and PPT after intervention. In future studies, it is necessary to investigate to what point the mechanical stimulation effect is maintained through the follow-up on the changes in CS after mechanical stimulation. Another limitation of this study is that the pressure applied to the cutaneous may have varied from person to person, resulting in differences in effectiveness. The current study suggests that the application of MI may propose a new pain treatment method if the degree of sensory changes and the PPT in the same spinal segment is studied.

\section{Conflict of Interest}

The authors declared no potential conflicts of interest with respect to the authorship and/or publication of this article.

\section{References}

1. Gerwin RD, Shannon S, Hong CZ, Hubbard D, Gevirtz R. Interrater reliability in myofascial trigger point examination. Pain 1997;69:65-73.

2. Pappagallo M. Aggressive pharmacologic treatment of pain. Rheum Dis Clin North Am 1999;25:193-213.

3. Russell IJ. Neurochemical pathogenesis of fibromyalgia syndrome. J Musculoskelet Pain 1996;4:61-92.

4. Hong CZ, Simons DG. Pathophysiologic and electrophysiologic mechanisms of myofascial trigger points. Arch Phys Med Rehabil 1998;79:863-72.

5. Simons DG. Review of enigmatic MTrPs as a common cause of enigmatic musculoskeletal pain and dysfunction. J Electromyogr Kinesiol 2004;14:95-107.

6. Wheeler AH. Myofascial pain disorders: theory to therapy. Drugs 2004;64:45-62.

7. Hammer WI. The effect of mechanical load on degenerated soft tissue. J Bodyw Mov Ther 2008;12:246-56.

8. Burke J, Buchberger DJ, Carey-Loghmani MT, Dougherty PE, Greco DS, Dishman JD. A pilot study comparing two manual therapy interventions for carpal tunnel syndrome. J Manipulative Physiol Ther 2007;30:50-61.

9. Solecki TJ, Herbst EM. Chiropractic management of a postoperative complete anterior cruciate ligament rupture using a multimodal approach: a case report. J Chiropr Med 2011;10: 47-53.

10. Mense S. How do muscle lesions such as latent and active trigger points influence central nociceptive neurons? J Musculoskelet Pain 2010;18:348-53.

11. Fernández-de-Las-Peñas C, Ge HY, Arendt-Nielsen L, Cuadrado ML, Pareja JA. Referred pain from trapezius muscle trigger 
points shares similar characteristics with chronic tension type headache. Eur J Pain 2007;11:475-82.

12. Srbely JZ, Dickey JP, Bent LR, Lee D, Lowerison M. Capsaicin-induced central sensitization evokes segmental increases in trigger point sensitivity in humans. J Pain 2010;11: 636-43.

13. Rivner MH. The neurophysiology of myofascial pain syndrome. Curr Pain Headache Rep 2001;5:432-40.

14. Kim Y, Kim J, Shim JK, Suh DW, Yoon B. The hypoalgesic effect of remote tactile sensory modulation on the mechanical sensitivity of trigger points: a randomized controlled study. NeuroRehabilitation 2014;35:607-14.

15. Cuypers K, Levin O, Thijs H, Swinnen SP, Meesen RL. Longterm TENS treatment improves tactile sensitivity in MS patients. Neurorehabil Neural Repair 2010;24:420-7.

16. Alonso-Blanco $\mathrm{C}$, Fernández-de-las-Peñas $\mathrm{C}$, Morales-Cabezas M, Zarco-Moreno P, Ge HY, Florez-García M. Multiple active myofascial trigger points reproduce the overall spontaneous pain pattern in women with fibromyalgia and are related to widespread mechanical hypersensitivity. Clin J Pain 2011;27:405-13.

17. Yap EC. Myofascial pain--an overview. Ann Acad Med Singapore 2007;36:43-8.
18. Ruiz-Sáez M, Fernández-de-las-Peñas C, Blanco CR, MartínezSegura R, García-León R. Changes in pressure pain sensitivity in latent myofascial trigger points in the upper trapezius muscle after a cervical spine manipulation in pain-free subjects. J Manipulative Physiol Ther 2007;30:578-83.

19. Leonard G, Goffaux P, Marchand S. Deciphering the role of endogenous opioids in high-frequency TENS using low and high doses of naloxone. Pain 2010;151:215-9.

20. Hollins M, Harper D, Maixner W. Changes in pain from a repetitive thermal stimulus: the roles of adaptation and sensitization. Pain 2011;152:1583-90.

21. Roussel NA, Nijs J, Meeus M, Mylius V, Fayt C, Oostendorp R. Central sensitization and altered central pain processing in chronic low back pain: fact or myth? Clin J Pain 2013;29:625-38.

22. Latremoliere A, Woolf CJ. Central sensitization: a generator of pain hypersensitivity by central neural plasticity. J Pain 2009;10: 895-926.

23. Wang C, Ge HY, Ibarra JM, Yue SW, Madeleine P, ArendtNielsen L. Spatial pain propagation over time following painful glutamate activation of latent myofascial trigger points in humans. J Pain 2012;13:537-45. 